\title{
A comparison of the efficacy and safety of daily inhaled budesonide/formoterol and as and when needed inhaled budesonide/formoterol combination in moderate persistent asthma
}

\author{
Priyanka Kumawat ${ }^{1}$, Mahesh Chand Gupta ${ }^{1}$, Dhruva Chaudhry ${ }^{2} *$
}

\begin{abstract}
${ }^{1}$ Department of Pharmacology, Pt. BD Sharma, PGIMS, Rohtak, Haryana, India ${ }^{2}$ Department of Pulmonary and critical care medicine (PCCM), Pt. BD Sharma, PGIMS, Rohtak, Haryana, India

Received: 13 July 2016 Accepted: 10 August 2016

*Correspondence to:

Dr. Priyanka Kumawat, Email:

kumawat.ricky@gmail.com

Copyright: (c) the author(s), publisher and licensee Medip Academy. This is an openaccess article distributed under the terms of the Creative Commons Attribution NonCommercial License, which permits unrestricted noncommercial use, distribution, and reproduction in any medium, provided the original work is properly cited.
\end{abstract}

\begin{abstract}
Background: To evaluate efficacy and safety of a fixed dose combination of budesonide/formoterol inhaler, when used as and when needed treatment approach in comparison with similar regimen daily.

Methods: A prospective, open label, parallel group study design, in which, screened patients, having moderate persistent asthma, underwent a 2 week of run in period, underwent randomization in two treatment groups, in one group daily treatment with fixed dose combination of budesonide/formoterol inhaler and in another group as and when needed treatment with similar medication. The assessments after baseline were done at 2, 4 and 6 weeks. The primary outcomes were Asthma Control Questionnaire Score (ACQS), asthma free days, exacerbation frequency and severity. Other outcomes were, lung functions, need for rescue medication, Modified Borg dyspnea score and patient preference on VAS.

Results: The mean age of 50 patients included in study was $40.24 \pm 2.38$ years in group I, and 39.24 \pm 1.81 years in group II. Patients were followed up for 6 weeks after 2 weeks of run in period. Improvement of ACQS, exacerbation prevention and number of asthma free days were same with both the regimens. Though the drugs taken in as and when needed treatment group was almost half of daily regimen group. Adverse drug reactions (ADRs) were not found in any group. No association between adverse effects and dose was established.

Conclusions: Both the treatment regimens improve the asthma control parameters, prevent exacerbations and prevent the decline in lung functions with the similar efficacy and safety. So as and when needed treatment approach can be an alternative to daily regimen for stable moderate persistent asthma patients.
\end{abstract}

Keywords: ACQS, Asthma free days, Exacerbations, Lung functions, Borg dyspnea score, VAS

\section{INTRODUCTION}

Asthma is a chronic problem throughout the world and its prevalence is increasing day by day. The international guidelines and a consensus reporter commend regular use of inhaled steroids for mild persistent asthma and regular use of inhaled steroids in combination with LABA (long acting beta 2 agonist) for moderate persistent asthma. Studies reporting that such treatment improves physiological measures of airway obstruction [peak expiratory flow (PEF) and forced expiratory volume in one second (FEV1)], severity of symptoms, frequency of exacerbations and may prevent progressive loss of pulmonary function. ${ }^{1-6}$ However, it has been seen that regularly prescribed medications to the patient, is usually not to be taken according to the prescription pattern because patients with controlled asthma has no or less on going symptoms in any situation and seldom needs to use reliever therapy, so low rates of regular use of these drugs measured by DDD (defined daily dose) and number of prescriptions dispensed indicate that most people who take these medications used them intermittently or as and when needed basis. ${ }^{7,9}$ It is not known if this is still effective and safe in controlling asthma symptoms. Since a very long time, the controversies rising, regarding comparative efficacy, safety and cost of daily and intermittent treatment regimens for asthma because of uncertain requirement of daily inhaled therapy in 
recurrent wheezing, intermittent and mild asthma, side effects of daily corticosteroids in toddlers and children, conflicts in disease modifying effect (lung functions, quality of life and airway remodelling) of corticosteroids, concerns. ${ }^{10,11}$ Besides it, the intermittent approach attracts the patients because of ease of compliance and lesser side effects. ${ }^{12,13}$ So a hypothesis has been generated that, the intermittent regimen can be an alternative to moderate persistent asthma. Few studies have been conducted on this issue to compare daily and intermittent regimen but the controversy still exists so as to whether the daily administration is better or an as and when needed treatment is better considering the efficacy, safety and costs. So there are two basic questions in minds of researchers 1) Does intermittent therapy with ICS provides significant clinical benefits compared with daily ICS; and 2) What are the risks of daily use of ICS compared with the intermittent-use strategy? ${ }^{14}$

In the present study it was analyzed that, whether this strategy could be an acceptable approach to treatment in adult patients with moderate persistent asthma. A modified symptom-based action plan was used to guide the use of budesonide+formoterol combination inhaler, when signs or symptoms of asthma appear, along with use of additional rescue puffs of similar medication. A comparison of the level of asthma control obtained with the use of these medications as and when needed treatment approach with that of daily treatment approach.

\section{METHODS}

\section{Study design and participants}

It was a prospective, randomized, open labelled, comparative, parallel group and single center clinical study. The study was performed in accordance with the declaration of Helsinki, and the protocol was approved by the local institutional review board and written informed consent was obtained from each participant. Patients were enrolled as per inclusion criteria i.e. patients between age of 18 to 60 years suffering from moderate persistent asthma as per ATS guidelines for at least 6 month before entry into the study, with significant bronchial reversibility $(12 \%+200 \mathrm{ml})$ and willing to participate were included. ${ }^{15}$ Exclusion criteria were severe exacerbations or previous hospitalization or emergency visits in previous 6 weeks, use of oral corticosteroids in past 2 weeks, current treatment with antibiotics for any upper respiratory tract infection, history of allergy or adverse drug reaction (ADR) to the drugs in study protocol, presence of lung disease other than asthma and any fixed airway diseases, presence of other significant medical illness, immunodeficiency disorders, pregnancy and lactation.

\section{Intervention}

The study duration was of 8 weeks, including 2 weeks of run in period. During 2-weeks of run-in period, all the patients received formonide-200 (A fixed dose combination of budesonide and formoterol) MDI (metered dose inhaler) (Zydus-Cadila), 1 puff twice a day to stabilize them at baseline. After completion of run in period all the patients were randomized into two treatment regimen groups, by computer generated randomized program. The treatment assigned in group I was daily formonide-200 (budesonide+formoterol combination) MDI (metered dose inhaler) 1 puff twice a day and in group II was as when needed formonide-200 (budesonide+formoterol combination) MDI (metered dose inhaler) 1 puff twice a day. Additional 4 puffs of rescue medicine (formonide-200) were allowed in both the groups on worsening of symptoms and during exacerbations. If $>4$ additional puffs were required, patients were asked to report to hospital and treated as per physician's advice. Patients requiring a change in medication or hospitalization were excluded from the study.

\section{Outcome measures}

The primary efficacy variables were Asthma Control Questionnaire score (ACQS), asthma free days, exacerbation frequency and severity. Secondary efficacy variables were lung functions [forced vital capacity (FVC), $\mathrm{FEV}_{1}, \mathrm{FEV}_{1} / \mathrm{FVC}$, peak expiratory flow rate (PEFR)], Need for rescue medications, Modified Borg Dyspnea Score (MBS) and patient preference on visual analog scale (VAS). Patients were assessed at the end of run in period, which was considered as baseline values ( 0 weeks), then at 2, 4 and 6 weeks.

ACQS assessed the degree of asthma control, by means of a seven-item questionnaire (in which a score of 0 indicated no symptoms and a score of 6 indicate severe symptoms). ${ }^{16}$ We modified the Asthma Control Questionnaire according to the use of rescue medications; if person had not used any rescue medication then the question was of no value and had not been counted in scoring. The asthma control was expressed by "Gaining Optimal Asthma Control" (GOAL) classification in which, score $\leq 0.75$ was well-controlled, 0.76 to 1.4 . Indeterminate and $\geq 1.50$ score mean not wellcontrolled. ${ }^{17}$ An asthma free day was 24 hour free of any asthma related symptoms, like cough, wheeze, chest tightness and discomfort and a 24-hour period without the use of rescue medications. ${ }^{18}$

An exacerbation is an episode, when there is progressive increase in number of episodes of shortness of breath, cough, night time awakenings, wheezing or a combination of above requiring rescue medication, a change in regular medication or hospitalizations. ${ }^{8}$ It is graded in severity as per GINA guidelines. Patients were asked to report to hospital if they were not controlled in spite of taking rescue medicine.

Modified Borg Dyspnea Score (MBS), it is a scale to measure severity of dyspnea graded from 0 to 10 score 
$(0=$ no dyspnea, $10=$ maximum dyspnea $)$

\section{Statistical analysis}

The data was collected and were subjected to appropriate descriptive and inferential statistics. All the observations were made and recorded as Mean \pm Standard error of mean (SEM). A ' $p$ ' value $<0.05$ was considered as statistically significant.

Homogeneity of treatment groups for age and sex were analyzed by chi-square test, both intragroup and intergroup statistical analysis was done. Intragroup analysis for repeated measures was done using ANOVA for parametric data and Friedman's test for nonparametric data. Intergroup analysis was done using independent't' test for parametric data and Mann Whitney $U$ test for non-parametric data. Categorical data like incidence of adverse events in both the groups were analyzed using Chi-square test or Fisher Exact test where appropriate.

\section{RESULTS}

\section{Study patients}

A total of 70 patients with moderate persistent asthma were screened, out of these, 18 patients were excluded as they did not match the predefined inclusion criteria mentioned in Flow chart (Figure 1). All the 50 completed patients had similar baseline characteristics (Table 1).

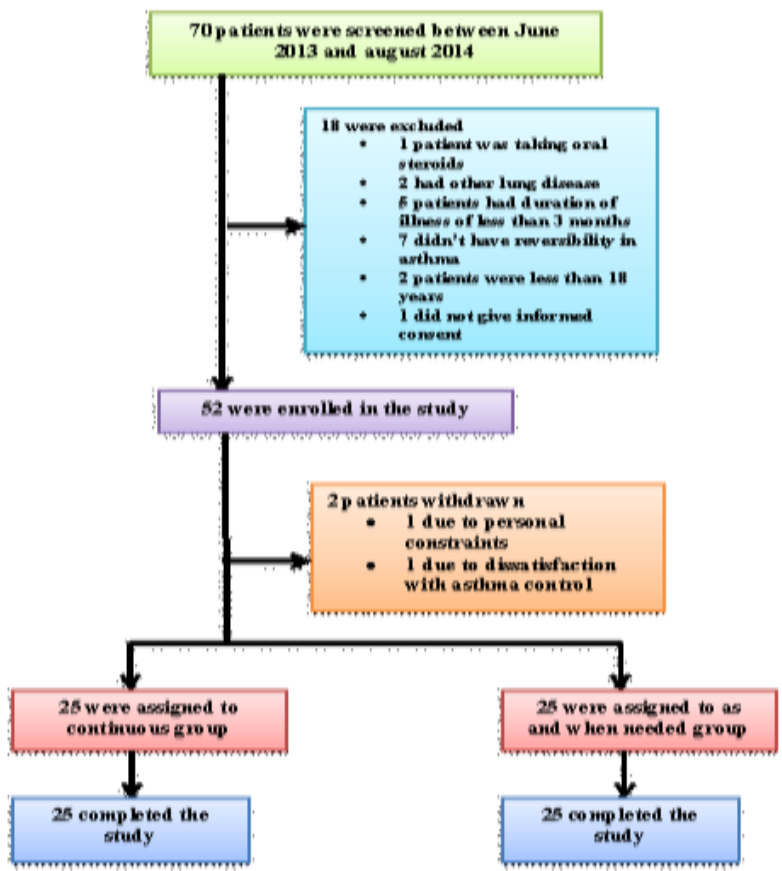

Patient eligibility, randomization, assignment and completion of the study.

Figure 1: Flow chart of the study.

Table 1: Demographic and clinical characteristics of patients.

\begin{tabular}{|c|c|c|c|}
\hline Demographic parameters & $\begin{array}{l}\text { Daily regimen group } \\
(\mathrm{n}=\mathbf{2 5})\end{array}$ & $\begin{array}{l}\text { As and when needed } \\
\text { regimen group }(n=25)\end{array}$ & P- Value \\
\hline Age (years) & $40.24 \pm 2.38$ & $39.24 \pm 1.81$ & 0.740 \\
\hline Female : male & $18: 7$ & $20: 5$ & NS \\
\hline Duration of illness (months) & $55.32 \pm 11.78$ & $76.80 \pm 21.49$ & 0.385 \\
\hline History of smoking & $0.20 \pm 0.20$ & $0.24 \pm 0.20$ & 0.889 \\
\hline Modified Borg dyspnea score & $2.00 \pm 0.28$ & $2.00 \pm 0.29$ & 0.961 \\
\hline ACQ & $2.05 \pm 0.15$ & $1.99 \pm 0.18$ & 0.797 \\
\hline FVC $(\%)$ & $79.40 \pm 1.43$ & $77.68 \pm 1.69$ & 0.431 \\
\hline Predicted $\mathrm{FEV}_{1}$ (liters) & $3.29 \pm 0.12$ & $3.12 \pm 0.13$ & 0.350 \\
\hline Predicted $\mathrm{FEV}_{1} / \mathrm{FVC}$ & $0.81 \pm 0.00$ & $0.81 \pm 0.00$ & 0.617 \\
\hline Pre BD FEV ${ }_{1}(\%)$ & $63.52 \pm 0.75$ & $63.88 \pm 0.92$ & 0.680 \\
\hline Post BD FEV $1(\%)$ & $74.60 \pm 1.04$ & $73.40 \pm 2.03$ & 0.602 \\
\hline Pre BD FEV $1 / F V C(\%)$ & $80.40 \pm 0.96$ & $81.92 \pm 1.23$ & 0.337 \\
\hline Post BD FEV $1 / F V C(\%)$ & $85.64 \pm 1.47$ & $89.60 \pm 1.26$ & 0.047 \\
\hline PEFR $(\%)$ & $63.76 \pm 3.02$ & $63.44 \pm 2.41$ & 0.590 \\
\hline Reversibility volume change in $\mathrm{FEV}_{1}(\mathrm{ml})$ & $325.20 \pm 29.04$ & $294.80 \pm 27.47$ & 0.451 \\
\hline Reversibility percentage change in $\mathrm{FEV}_{1}(\%)$ & $18.45 \pm 1.01$ & $16.90 \pm 1.00$ & 0.300 \\
\hline
\end{tabular}

\section{Primary outcomes}

According to GOAL classification for ACQS, asthma was poorly controlled at 0 and 2 weeks ( $\geq 1.50$ score), which significantly improved to partially controlled (indeterminate) at 4 and 6 weeks ( 0.76 to 1.4 score) with both the treatment groups. A significant improvement was found in the ACQ scores in group I patients at 2 
weeks $(p=0.045)$ and highly significant at 4 weeks $(p=0.006)$ as well as at 6 weeks $(p=0.000)$. The scores were significantly improved in group II patients at 4 weeks $(p=0.020)$ and 6 weeks $(p=0.002)$, however, the improvement was not significant at 2 weeks $(\mathrm{p}=0.583)$. Both the treatment regimens improved ACQ score to the same extent at clinical visits, with the $\mathrm{p}$ values 0.858 , 0.974 and 0.501 at 2,4 and at 6 weeks respectively (Figure 2). The proportion of asthma free days (AFD) across the study was $91.6 \%$ with daily regimen and $92.95 \%$ with as and when needed regimen, with nonsignificant difference of improvement in AFD at 2 weeks $(\mathrm{p}=0.708), 4$ weeks $(\mathrm{p}=0.802)$ and at 6 weeks $(\mathrm{p}=0.824)$ in between 2 groups (Figure 3$)$.

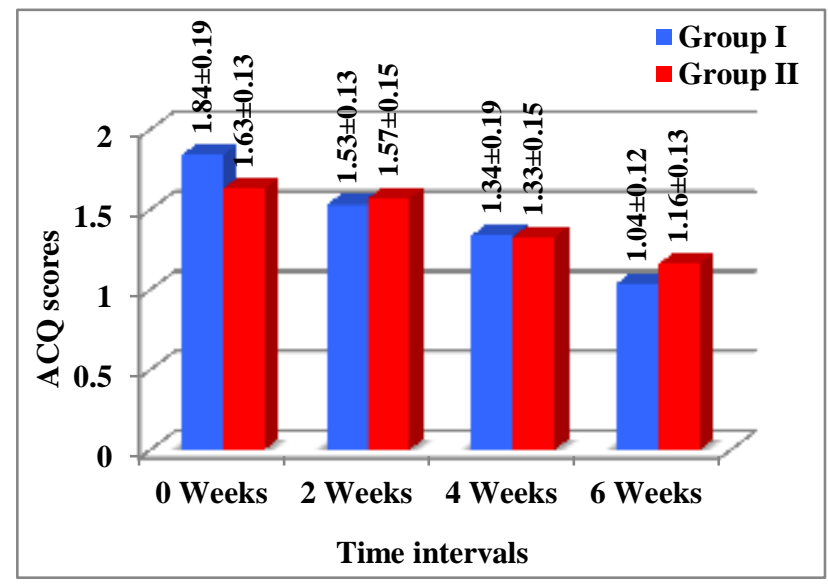

Figure 2: Asthma control questionnaire score (ACQS) changes at different time intervals.

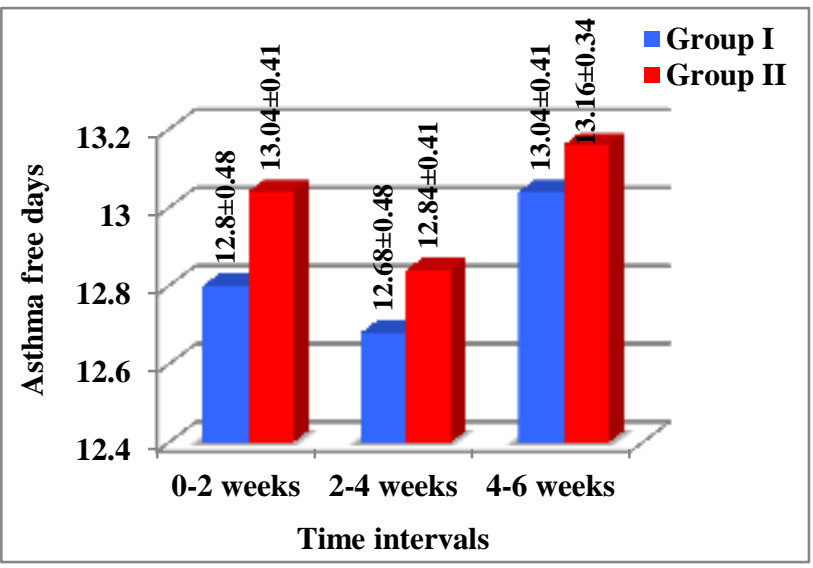

Figure 3: Asthma free days (AFD) at different time intervals.

There was no significant difference between a daily regimen and as and when needed regimen, with respect to frequency and severity of exacerbations at any visit $(p>0.05)$. Only mild category of exacerbations were observed in both the groups, total 4 exacerbations occur in patients on daily regimen while 7 exacerbations occur in patients on as and when needed regimen. Along with that there was similar use of rescue medication in both the groups with the nonsignificant difference $(p>0.05)$.

\section{Secondary outcomes}

With both the treatment regimens there was no significant change $(\mathrm{p}>0.05)$ in lung functions $\left(\mathrm{FEV}_{1}, \mathrm{FEV}_{1} / \mathrm{FVC}\right.$ and PEFR) was observed.

Fifty four \% less rescue medicine intake was observed with as and when needed strategy than daily strategy. However, when compared both regimens found to be statistically equivalent in rescue intake at every clinical visit.

Modified Borg dyspnea score (MBS) improved to the same extent by both the regimens with significant improvement in daily regimen group at 2 weeks $(\mathrm{p}=0.001), 4$ weeks $(\mathrm{p}=0.002)$ and at 6 weeks $(\mathrm{p}=0.001)$ and in as and when needed group, significant at 4 weeks $(\mathrm{p}=0.047)$ and highly significant at 6 weeks $(\mathrm{p}=0.001)$. However, at 2 weeks the improvement was not significant with as and when needed regimen (Figure 4).

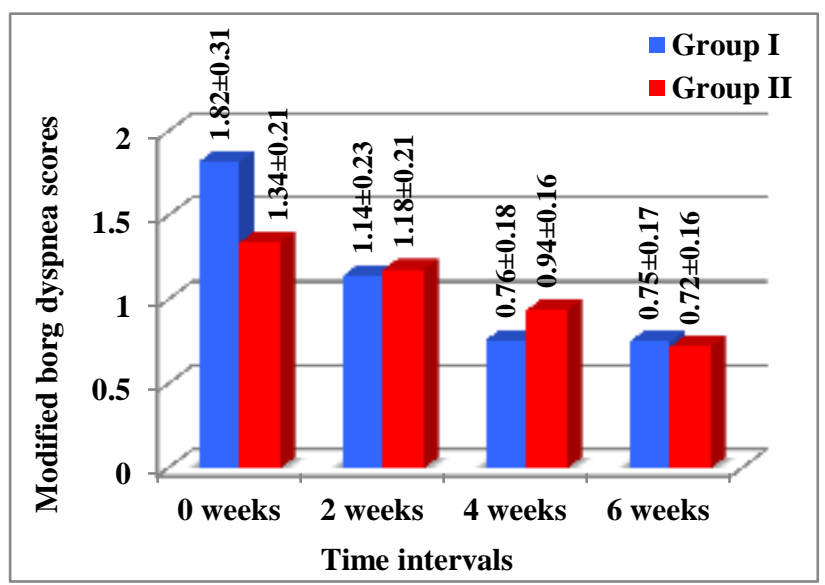

Figure 4: Modified BORG dyspnea score (MBS) changes at different time intervals.

When global patient preference on Visual analog scale (VAS) was assessed, the daily regimen was significantly more preferred by the patients than the as and when needed regimen.

\section{Safety evaluation}

Both the regimens were found to be equivalent in terms of safety. Only throat irritation was present in one patient at 2 weeks with as and when needed treatment, which was of category I and improved over the time. Otherwise none of the patient suffered from any drug related side effect like tremors, palpitation, restlessness, nervousness, throat irritation, ankle edema, hoarseness of voice, dysphonia, oropharyngeal candidiasis, mood changes, bone pain, bruising, petechiae, hyperglycemia and others during the course of the study. 


\section{DISCUSSION}

As per clinical scenario, many asthma patients remain inadequately controlled, despite the good efficacy of available medicine and continue to suffer a reduced quality of life as a result of their disease. Although these medicines have adverse effects, which lead to increased morbidity, some of them even increase the mortality. It is therefore imperative to develop new approaches to asthma therapy, with a view not only to control the disease efficaciously but also to an improved quality of life with minimum number of side effects of drugs. ${ }^{19}$

It has been seen that patients are less adherent to treatment and most of the patients take the medicines, whenever they are symptomatic only, otherwise not. Few studies have been conducted to compare the daily or "continuous regimen" with the "as and when needed" or intermittent regimen for asthma management. Not much difference was found between these two regimens in studies, in fact with the lesser concentration of drug per year, the intermittent regimen turn out to be better in terms of safety.

Boushey et al. found a better ACQ score improvement with continuous budesonide use as compared to as and when needed budesonide use in mild persistent asthmatics. ${ }^{20}$ However, in the present study both the groups had almost same impact on ACQ score improvement although there was late response (at 4 week) obtained in as and when needed therapy. The probable reason is patient's tendency to take medicine only when the symptoms become severe enough to tolerate, in as and when needed group. Likewise, Turpeinen et al. concluded similar effect of both the strategies. ${ }^{18}$

According to Papi et al. asthma free days (AFD) were equally improved in both the groups. ${ }^{21}$ Likewise Zeiger et al. said that improvement in AFD was not much different in daily and intermittent budesonide use in young children. ${ }^{22}$ The present study go in favour of Zeiger et al. and Papi et al. and observed that both the treatment regimens were equally effective in improving AFD, probably the occurrence of exacerbations was same and also no significant difference in need for rescue medication. ${ }^{21,22}$ Indeed there is increasing evidence that glucocorticoids have a relatively rapid suppressive effect on inflammation and the prn (pro re nata) combination treatment could be easier than a fixed daily antiinflammatory regimen, thus encouraging adherence. ${ }^{23}$

Exacerbations are clinically identified by being outside the patient's usual range of day-to-day asthma variation. Turpeinen et al. who compared only budesonide in children with mild persistent Asthma, found fewer exacerbations during months 7-18 with continuous regimen than as and when needed regimen. Sposato et al. compared budesonide in combination with bronchodilator as daily and intermittent regime in adults with mild to moderate persistent asthma found daily treatment better to prevent asthma related exacerbations. ${ }^{18,24}$ While in Papi et al. and Boushey et al. who compared budesonide as daily and as needed regimen, observed that both regimens were equivalent in terms of preventing asthma exacerbations. ${ }^{20,21}$ Present study also found that the incidence of occurrence of exacerbations were almost similar with both the treatment groups. The probable reason being proper and an equal use of rescue medicine in both the groups.

The lung functions although not improved significantly but they were static throughout the study duration. So the overall impressions of both the regimens are equally effective in preventing further decline in lung functions, over 6 weeks of period. Papi et al. found an equal improvement in FEV1 with both the strategies and more improvement in FVC with intermittent use of combination therapy. ${ }^{21}$ Likewise Boushey et al. declared an equal improvement in morning PEFR with both the daily and intermittent use of budesonide. ${ }^{20}$ While according to Turpeinen et al. there was a greater improvement in FEV1 with continuous regimen.18 Sposato et al. conclude that both strategies showed similar effect on lung functions and even a 4-year period of time is insufficient to assess the decline in FEV1 in asthma. ${ }^{24}$ But a 8 -week period is probably not long enough to understand if the two treatments can influence the improvement in lung functions in a different way. This is possibly because of the delayed effect of inhaled corticosteroids on remodelling. The beneficial effects of it on remodelling when observed, achieved only after 12 months of treatment, much slower than their antiinflammatory effect. ${ }^{25}$

Rescue medication intake was also similar with both the treatment regimens. The reason may be similar control of asthma related symptoms as per assessed by Asthma control questionnaire (ACQ) scores and Modified Borg dyspnea score (MBS) with both the regimens. Papi et al. and turpeinen et al. also observed the similar effect. ${ }^{18,26}$ However, in Papi et al. a lesser number of rescue medicines were required with intermittent strategy. ${ }^{21}$

In the present study, modified Borg dyspnea score was definitely improved with time in both the treatment regimens and reduction in the perception of dyspnoea by the patient, improvement was a little earlier (from 2nd week) with continuous use of therapy as compared to as and when needed therapy. Intergroup comparison declared both the regimen equally efficacious in improving Borg dyspnea score.

Observations of VAS seems that, Patients on continuous therapy were more satisfied with their treatment than the patients on as and when needed therapy, the reason probably being early control of asthma related symptoms as assessed by asthma control questionnaire score and Borg dyspnea score with continuous therapy. 
If we see total intake of medicines it was significantly low $(\mathrm{p}=0.000)$ in as and when needed group in comparison to daily treatment but there was no correlation found between adverse drug reactions and total drug intake. Probably the 8 week duration is not enough for the occurrence of ADRs, hence the correlation could not be applied. Even the real sparing effect of as and when needed combination cannot be established in this study, as we did not titrate the dose of inhaled glucocorticoid and formoterol in the combination, we believe that our findings are of interest. In fact, because, (a) discontinuation rates of regular asthma medications are very high, (b) the common overreliance on bronchodilators alone is associated with increased morbidity and mortality 28 and (c) the overall effect of regular inhaled glucocorticoids is modest, so it is suggest that as and when needed (prn) combination should be considered and further investigated as a treatment option. $^{27}$

The overall impression of the present study is that, both the treatment strategies i.e. daily budesonide/formoterol combination and as and when needed budesonide/formoterol combination by inhalational route were equally effective as far as improving ACQ score, controlling exacerbations, asthma free days, improvement of the lung functions, need for rescue medication, modified borg dyspnea score, safety and tolerability is concerned.

\section{CONCLUSION}

Since as and when needed budesonide and formoterol combination regimen showed almost similar results, to daily regimen in terms of efficacy and safety with significantly lesser use of drugs. It seems that as and when needed regimen can be an alternative to continuous therapy, with the use of rescue medications during worsening of symptoms in management of moderate persistent asthma. However, patients on daily therapy were found to be more satisfied with their regimen.

\section{Limitations}

It was conducted in a single hospital, so the results may not be generalizable. However, all the patients enrolled were registered in the study hospital as asthma patients for a minimum of previous 6 months and the institute was a tertiary referral center. The real sparing effect of as and when needed combination cannot be established in this study, as we did not titrate the dose of inhaled glucocorticoid. It could also be argued that a shorter study period might have not allowed us to detect a higher number of exacerbations and drug related side effects.

\section{ACKNOWLEDGEMENT}

Kind acknowledgement to Dr. Harish Kumar to support in giving final touch to this article and Zydus cadila to provide study medications (Budesonide + formoterol).
Funding: No funding sources

Conflict of interest: None declared

Ethical approval: The study was approved by the Institutional Ethics Committee

\section{REFERENCES}

1. Haahtela $\mathrm{T}$, Järvinen $\mathrm{M}$, Kava $\mathrm{T}$, Kiviranta $\mathrm{K}$, Koskinen S, Lehtonen K. Comparison of a beta 2agonist, terbutaline, with an inhaled corticosteroid, budesonide, in newly detected asthma. N Engl J Med. 1991;325(6):388-92.

2. Pauwels RA, Pedersen S, Busse WW, Tan WC, Chen YZ, Ohlsson SV. Early intervention with budesonide in mild persistent asthma: a randomised, double-blind trial. Lancet. 2003;361(9363):1071-6.

3. O'Byrne PM, Barnes PJ, Rodriguez-Roisin R, Runnerstrom E, Sandstrom T, Svensson K. Low dose inhaled budesonide and formoterol in mild persistent asthma: the OPTIMA randomized trial. Am J RespirCrit Care Med. 2001;164(8):1392-7.

4. Haahtela $\mathrm{T}$, Järvinen $\mathrm{M}$, Kava $\mathrm{T}$, Kiviranta $\mathrm{K}$, Koskinen S, Lehtonen K. Effects of reducing or discontinuing inhaled budesonide in patients with mild asthma. N Engl J Med. 1994;331(11):700-5.

5. Selroos $\mathrm{O}$, Pietinalho $\mathrm{A}$, Löfroos $\mathrm{AB}$, Riska $\mathrm{H}$. Effect of early vs late intervention with inhaled corticosteroids in asthma. Chest. 1995;108(5):122834.

6. Agertoft L, Pedersen S. Effects of long-term treatment with an inhaled corticosteroid on growth and pulmonary function in asthmatic children. Respir Med. 1994;88(5):373-81.

7. Jindal SK, Gupta D, Aggarwal AN, Agarwal R. World Health Organization; Government of India. Guidelines for management of asthma at primary and secondary levels of health care in india (2005). Indian J Chest Dis Allied Sci. 2005;47(4):309-43.

8. GINA Board of directors and Science Committee members. Global strategy for asthma management and prevention: Update. Vancouver: Global Initiative for Asthma. 2012. Available from URL: http://www.inaasthma.org.

9. Gillisen A. Patient's adherence in asthma. J PhysiolPharmacol. 2007;58(5):205-22.

10. Ducharme FM. Continuous versus intermittent inhaled corticosteroids for mild persistent asthma in children: not too much, not too little. Thorax. 2012;67(2):102-5.

11. Turpeinen M, Pelkonen AS, Selroos O, Nikander K, Haahtela T. Continuous versus intermittent inhaled corticosteroids for mild persistent asthma in children: not too much, not too little. Thorax. 2012;67(2):100-2.

12. Rabe KF, Adachi M, Lai CK, Soriano JB, Vermeire PA, Weiss KB. Worldwide severity and control of asthma in children and adults: the global asthma insights and reality surveys. J Allergy ClinImmunol. 2004;114(1):40-7. 
13. Pando $\mathrm{S}$, Lemière $\mathrm{C}$, Beauchesne MF, Perreault $\mathrm{S}$, Forget A, Blais L. Suboptimal use of inhaled corticosteroids in children with persistent asthma: inadequate prescription, poor drug adherence, or both? Pharmacotherapy. 2010;30(11):1109-16.

14. Rodrigo GJ, Castro-Rodríguez JA. Daily vs. intermittent inhaled corticosteroids for recurrent wheezing and mild persistent asthma: A systematic review with meta-analysis. Respir Med. 2013;107(8):1133-40.

15. National Asthma Education and Prevention Program Coordinating Committee. The Expert Panel Report 3 (EPR-3) Summary Report. Guidelines for the diagnosis and management of asthma. New York: National Heart, Lung, and Blood Institute. 2007.

16. Juniper EF, O'byrne PM, Ferrie PJ, King DR, Roberts JN. Measuring asthma control clinic questionnaire or daily diary? Am J RespirCrit Care Med. 2000;162(4):1330-4.

17. Leite M, Ponte EV, Petroni J, D'OliveiraJúnior A, Pizzichini E, Cruz AA. Evaluation of the Asthma Control Questionnaire validated for use in Brazil. J Bras Pneumol. 2008;34(10):756-63.

18. Turpeinen M, Nikander K, Pelkonen AS, Syva“nen P, Sorva R, Raitio H. Daily versus as-needed inhaled corticosteroid for mild persistent asthma (The Helsinki early intervention childhood asthma study). Arch Dis Child. 2008;93(8):654-9.

19. Tattersfield AE, Knox AJ, Britton JR, Hall IP. Asthma. Lancet. 2002;360(9342):1313-22.

20. Boushey HA, Sorkness CA, King TS, Sullivan SD, Fahy JV, Lazarus SC. Daily versus as-needed corticosteroids for mild persistent asthma. N Engl J Med. 2005;352(15):1519-28.
21. Papi A, Canonica GW, Maestrelli P, Paggiaro P, Olivieri D, Pozzi E. Rescue use of beclomethasone and albuterol in a single inhaler for mild asthma. $\mathrm{N}$ Engl J Med. 2007;356(20):2040-52.

22. Zeiger RS, Mauger D, Bacharier LB, Guilbert TW, Martinez FD, Lemanske RF. Daily or intermittent budesonide in preschool children with recurrent wheezing. N Engl J Med. 2011;365(21):1990-2001.

23. Barnes PJ. Scientific rationale for using a single inhaler for asthma control. Eur Respir J. 2007;29(3):587-95.

24. Sposato B, Pammolli A, Bove L, Barzan R, Ricci A, Scalese M. A regular or an intermittent treatment for asthma: the long-term effect. Eur Rev Med Pharmacol Sci. 2010;14(12):1037-44.

25. Ward C, Pais M, Bish R, Reid D, Feltis B, Johns D. Airway inflammation, basement membrane thickening and bronchial hyper responsiveness in asthma. Thorax. 2002;57(4):309-16.

26. Papi A, Nicolini G, Baraldi E, Boner AL, Cutrera R, Rossi GA. Regular vs prn nebulized treatment in wheeze preschool children. Allergy. 2009;64(10):1463-71.

27. Zuidgeest MG, Smit HA, Bracke M, Wijga AH, Brunekreef B, Hoekstra MO. Persistence of asthma medication use in preschool children. Respir Med. 2008;102(10):1446-51.

28. Butz AM, Tsoukleris M, Donithan M, Hsu VD, Mudd K, Zuckerman IH. Patterns of inhaled antiinflammatory medication use in young underserved children with asthma. Pediatrics. 2006;118(6):2504-13.

Cite this article as: Kumawat $\mathrm{P}$, Gupta MC, Chaudhry D. A comparison of the efficacy and safety of daily inhaled budesonide/formoterol and as and when needed inhaled budesonide/formoterol combination in moderate persistent asthma. Int $\mathbf{J}$ Basic Clin Pharmacol 2016;5:2103-9. 